\title{
Factors associated with unfavorable outcomes caused by Syphilis infection in pregnancy
}

Maria Alix Leite Araújo 1

Dttps://orcid.org/0000-0002-4156-5783

Roumayne Fernandes Vieira Andrade 2

D.tps://orcid.org/0000-0003-0477-206X

Valéria Lima de Barros 3

https://orcid.org/0000-0002-5109-9800

Paula Manuela Rodrigues Pinheiro Bertoncini 4

D https://orcid.org/0000-0001-9078-0175

1 Programa de Pós Graduação em Saúde Coletiva. Universidade de Fortaleza. Fortaleza, Ceará, Brasil.

2 Faculdade de Ciências Médicas de Campina Grande. Av. Sen. Argemiro de Figueiredo, 1901 - Itararé, Campina Grande - PB, CEP: $58411-020$.

E-mail: roumaynefv@hotmail.com

3 Universidade Federal do Piauí. Picos, Piauí, Brasil.

4 Faculdade Integrada da Grande Fortaleza. Fortaleza, Ceará, Brasil.

\begin{abstract}
Objective: to analyze factors associated with unfavorable outcomes caused by syphilis infection in pregnancy.

Methods: descriptive study carried out from May to August 2014, in public maternity hospitals. A questionnaire was administered to all women with a reactive Venereal Disease Research Laboratory (VDRL) test result and the data were supplemented with information from medical records and prenatal files. The bivariate analysis was performed using Pearson's chi-square or Fisher's exact test. For the multivariate analysis, was used through the logistic regression model.

Results: a total of 137 puerperal women participated in the study, of which $14.3 \%$ had an unfavorable outcome, namely: stillbirth (2.9\%), preterm birth (8.8\%) and low birth weight $(2.9 \%)$. In the multivariate analysis the odds ratio for the prevalence of an unfavorable outcome was three-fold higher in women who did not undergo a second VDRL test $(O R=3,54$; IC95\% 1,04-15,33) and two-fold higher in women with a VDRL titer $>1: 8(O R=2,15 ;$ IC95\% $1,11-11,2)$.

Conclusions: The unfavorable outcomes occurred in women who did not undergo the second VDRL test and those whose VDRL titer was $>1: 8$ performed in the maternity hospital. Key words Syphilis, congenital, Syphilis, Pregnant Woman, Outcome
\end{abstract}




\section{Introduction}

It is estimated that 1.5 million cases of syphilis occur worldwide in pregnant women every year, ${ }^{1}$ in which such situations can have severe consequences for the newborn, as prematurity, stillbirths, early or late congenital manifestations and/or death of the newborn. ${ }^{2}$ Eliminating Congenital Syphilis (CS) seems to be a far reality in being attained in poor and developing countries, such as Brazil. In the United States, a research that analyzed 6,383 cases of CS notified the Centers for Disease Control and Prevention (CDC), between 1999 and 2013, identifying rates of mortality at $6.5 \%$ and morbidity at $33.6 \%$. Among the registered deaths, $89 \%$ of the mothers were not treated or were inadequately treated. ${ }^{3}$

In Brazil, only in 2016, 19,846 cases of CS were diagnosed and a total of 185 dead children under one year of age were reported to the Sistema de Informações sobre Mortalidade (SIM) (Mortality Information System), which corresponded to a coefficient mortality rate of 6.1 per 100,000 live births. Moreover, the child mortality rate for CS increased from 2.0/100,000 in 2006 to 6.8/100,000 live births in 2016 . The Northeast region registered $31 \%$ of all the reported cases and Ceará State is among the ten Brazilian States with the highest incidence rate of CS when compared to the national rate $(8.6 / 1,000$ live births). ${ }^{4}$ These indicators exceeded the goal recommended by the World Health Organization (WHO), 5 by indicating the need for effective actions in confronting the problem.

The persistence of CS as a public health problem in Brazil is a consequence of the lack of effective prevention and control actions. After all, the disease is an entirely preventable infection, considering that it can be easily identified and treated in pregnant women. However, the operational dynamic and the prenatal care at the primary care services have not caused an impact in reducing its incidence. 6

The high incidence of the disease is associated to social issues such as low maternal schooling and skin color, as well as health care factors such as initiate late prenatal care, fewer number of consultations and fewer performance of serological tests. 7 Studies show that delayed diagnosis, lack of or inadequate treatment for pregnant women are the main difficulties found to reduce vertical transmission of syphilis. 8,9

Considering the aforementioned problems, this study aimed to analyze the factors associated with the unfavorable outcomes caused by syphilis during pregnancy.

\section{Métodos}

This is a quantitative and descriptive study carried out at seven public maternity hospitals in Fortaleza city in Ceará state (four municipals, two states and one federal maternity hospital). Three of them are referral hospitals for high-risk deliveries and all of them perform the Venereal Disease Research Laboratory (VDRL) test as an admission routine for childbirth. These services were responsible for practically almost all the births that occurred in the municipality in 2013 and for the $83 \%$ of the reported cases of CS from January to June of 2014.

The data collection occurred from May to August 2014, through a questionnaire that was applied and included all the women who were in the hospital wards and had a VDRL reagent test. The data were completed with the information from the medical files and the prenatal cards. The data collection instrument was pre-tested and subsequently, performed the necessary adjustments. Properly trained Nursing undergraduate students who made daily visits to the maternity to interview the women, participated in the data collection. All the variables of the instrument were predefined and discussed with the students for the calibration procedures of the data collection.

The questionnaire included sociodemographic variables (origin, age group, years of schooling, family income, number of sexual partners, whether the partner is the baby's father, whether she is or was a homeless person); and prenatal care (gestational week at the start of the prenatal, number of consultations, the VDRL titration test during gestation, gestational week at the 1st and 2nd VDRL tests, performance of adequate treatment, performed monthly VDRL tests, serology results for HIV, the VDRL titration test at the moment of childbirth).

The unfavorable outcome variable resulted from the combination of the following situations: premature births, low birth weight newborns and stillbirths. Premature birth was considered when the babies were born before 37 weeks of gestation; low birth weight newborns were those weighing at birth $<2500 \mathrm{~g}$; stillbirths are those when the fetus death occurred prior to expulsion or completely removed from the mother's body with a birth weight equal or superior of 500 grams and / or gestational age of 22 weeks or older. 10

Women who had some type of gestational risk factor (pre-eclampsia, eclampsia, gestational bleeding, urinary infection, rubella, toxoplasmosis, use of medication to induce abortion or use of drugs during pregnancy) were excluded, since such 
circumstances can also lead to unfavorable outcomes and therefore be mistaken by those related to syphilis. ${ }^{11}$

During the study period, a total of 216 women with VDRL reagent test were admitted to these maternities at the time of childbirth. Of these, 137 women participated in the research and 67 were excluded (61 were excluded because they used some type of illicit drug during pregnancy and/or used medication to induce abortion; and six were diagnosed with preeclampsia) and 12 refused to answer the questionnaire.

Data were entered into the Statistical Package for the Social Sciences (SPSS) software, version 23. A bivariate analysis was performed, and Pearson's chisquare or Fisher's exact test was used for the diffe-rences among the categorical variables with the level of significance of $5 \%$ with $95 \%$ confidence interval. Subsequently, a multivariate analysis was performed by using the statistical package STATA, version 15, and through the logistic regression model used the stepwise technique. The variables with a value of $p<0.05$ were used for the adjusted analysis The Odds Ratio (OR) was used as a measurement effect with a $95 \%$ confidence interval $(95 \% \mathrm{CI})$.

This study was approved by the Research Ethics Committee at the Universidade de Fortaleza (UNIFOR), protocol number 468.751. All the participants signed the Free and Informed Consent Form.

\section{Results}

Among the parturients, 20 (14.6\%) presented some type of unfavorable outcome ( $8.8 \%$ premature birth, $2.9 \%$ stillborn and $2.9 \%$ low birth weight newborns). Table 1 shows the sociodemographic and prenatal care variables.

The age ranged from 14 to 48 years old (mean age was 24 years old; $\mathrm{SD}=6.8$ ) and a little more than half of the women were in the 19-29 age group $(59.9 \%)$. A total of $108(78.8 \%)$ women self-reported their ethnicity as non-white, $119(86.9 \%)$ reported living in the municipality of Fortaleza, 108 (78.8\%) reported having a partner, $123(89.8 \%)$ reported having a personal income lower than a minimum wage and $49(35.1 \%)$ reported being employed. Two $(1.5 \%)$ presented a reagent result for HIV at the time of childbirth (data not shown in the table).

Age less than 29 years old $(p=0.01)$ and family income less than two minimum wages $(p=0.05)$ were the variables that presented a statistically significant association with the occurrence of an unfavorable outcome in women with VDRL reagent test (Table 2).
The variables related to the unfavorable outcomes and prenatal care aspects, performing the VDRL test and the treatment for pregnant women are shown in Table 3 . The number of prenatal consultations equal or superior six $(p=0.03)$; the performance of a second VDRL test during prenatal care $(p=0.03)$ and the VDRL titration test greater than 1:8 at the maternity hospital $(p=0.05)$ all showed statistical significance.

The adjusted multivariate logistic regression analysis of the factors associated with unfavorable outcomes in parturients with VDRL reagent test (Table 4) indicates that the prevalence of the odds ratios present some unfavorable outcome was three times higher in women who did not undergo a second VDRL test $(\mathrm{OR}=3.54,95 \% \mathrm{CI}=1.04-15.33)$ and twice as high in women whose VDRL titration was greater than $1: 8(\mathrm{OR}=2.15 ; 95 \% \mathrm{CI}=1.11-11.2)$.

\section{Discussion}

Although it is very important to collaborate with actions in preventing the vertical transmission of syphilis, thus, the data on the unfavorable outcomes caused by CS are still scarce in Brazil. The difference in the prevalence of the outcomes in parturients with VDRL reagent test (14.6\%), when compared to another study 7 carried out in Brazil, may be related to the concept of the outcome variable. Domingues and Leal 7 , found a rate of $17 \%$ for some type of unfavorable outcome. The authors included cases on neonatal ICU admission, which the outcome was not considered in this study.

The possibility of transmitting syphilis to the baby is related to the mother's stage of infection. A large number of women with VDRL titration equal to or less than 1:8 was identified, in which may not represent an active infection. High VDRL titration may lead to increased fetal impairment 12 and unfavorable outcomes. 3,13 A study that calculated the worldwide estimate of adverse effects caused by syphilis during pregnancy showed that approximately 1.36 million pregnant women had active syphilis and, of these, 520,905 presented some adverse effect caused by the infection. 14

The profile of pregnant women with syphilis in the present study corroborates with findings from other studies, which show that young women with low schooling levels and low income are more vulnerable to acquire Sexually-Transmitted Infections (STIs), especially syphilis.7,15 Moreover, it is a vulnerable population, which probably had difficulties in having access to healthcare services, a situation most frequently seen among individuals 
Table 1

Parturients' socioeconomic and prenatal care variables admitted at public maternities in Fortaleza, Ceará, 2014.

\begin{tabular}{|c|c|c|c|}
\hline Variables & $\bar{X} \pm S D$ & $\mathbf{N}$ & $\%$ \\
\hline Age range (in years) & $24.6 \pm 6.8$ & & \\
\hline$\leq 18$ & & 28 & 20.4 \\
\hline$>19$ & & 109 & 79.6 \\
\hline Schooling (in years) & $7.5 \pm 2.9$ & & \\
\hline$\leq 9$ & & 101 & 73.7 \\
\hline$>9$ & & 36 & 26.3 \\
\hline Family income (minimum wages) $(n=129)$ & $1.068 .8 \pm 691.1$ & & \\
\hline$\leq 1$ & & 56 & 43.4 \\
\hline$>1$ & & 73 & 56.6 \\
\hline \multicolumn{4}{|l|}{ Received prenatal care } \\
\hline Yes & & 134 & 97.8 \\
\hline No & & 03 & 2.2 \\
\hline Initiated Prenatal care (in weeks) $(n=134)$ & $15.5 \pm 6.5$ & & \\
\hline$\leq 13$ & & 62 & 46.2 \\
\hline$>13$ & & 72 & 53.8 \\
\hline Number of Prenatal care consultations & $6.2 \pm 2.4$ & & \\
\hline$<6$ & & 63 & 46.0 \\
\hline$\geq 6$ & & 74 & 54.0 \\
\hline \multicolumn{4}{|c|}{ Was tested for VDRL during prenatal care $(n=134)$} \\
\hline Yes & & 123 & 91.8 \\
\hline No & & 11 & 8.2 \\
\hline \multicolumn{4}{|l|}{ Was tested for VDRL in the 1 st trimester $(n=109)$} \\
\hline Yes & & 54 & 49.5 \\
\hline No & & 55 & 50.5 \\
\hline \multicolumn{4}{|l|}{ 1st VDRLtitration $(n=97)$} \\
\hline$\leq 1: 8$ & & 60 & 61.9 \\
\hline$>1: 8$ & & 37 & 38.1 \\
\hline \multicolumn{4}{|l|}{ Was tested for the 2nd VDRL $(n=123)$} \\
\hline Yes & & 59 & 48.0 \\
\hline No & & 64 & 52.0 \\
\hline \multicolumn{4}{|l|}{ Was adequately treated } \\
\hline Yes & & 46 & 33.6 \\
\hline No & & 91 & 66.4 \\
\hline \multicolumn{4}{|l|}{ VDRL titration at the Maternity } \\
\hline$\leq 1: 8$ & & 105 & 76.6 \\
\hline$>1: 8$ & & 32 & 23.4 \\
\hline Total & & 137 & 100.0 \\
\hline
\end{tabular}

$\mathrm{SD}=$ Standard Deviation, $\mathrm{VRDL}=$ Venereal Disease Research Laboratory. 


\section{Table 2}

Unfavorable outcomes in pregnant women with VDRL reagent test admitted at public maternities according to sociodemographic variables. Fortaleza, Ceará, 2014.

\begin{tabular}{|c|c|c|c|c|c|}
\hline \multirow{3}{*}{ Variables } & \multicolumn{4}{|c|}{ Unfavorable outcome } & \multirow{3}{*}{$P$} \\
\hline & \multicolumn{2}{|c|}{ Yes } & \multicolumn{2}{|c|}{ No } & \\
\hline & $\mathrm{n}$ & $\%$ & $\mathrm{n}$ & $\%$ & \\
\hline Age (in years) & & & & & 0.01 \\
\hline$\leq 29$ & 20 & 100.0 & 91 & 77.8 & \\
\hline$>29$ & 00 & 0.0 & 26 & 22.2 & \\
\hline Schooling (in years) & & & & & 0.49 \\
\hline$\leq 9$ & 16 & 80.0 & 85 & 72.6 & \\
\hline$>9$ & 04 & 20.0 & 32 & 27.4 & \\
\hline Self-reported of skin color/ethnicity & & & & & 0.18 \\
\hline White & 02 & 10.0 & 27 & 23.1 & \\
\hline Non-white & 18 & 90.0 & 90 & 76.9 & \\
\hline Origin & & & & & 0.32 \\
\hline Fortaleza & 16 & 80.0 & 103 & 88.0 & \\
\hline Countryside & 04 & 20.0 & 14 & 12.0 & \\
\hline Has a partner & & & & & 0.10 \\
\hline Yes & 13 & 65.0 & 95 & 81.2 & \\
\hline No & 07 & 35.0 & 22 & 18.8 & \\
\hline Personal income (Minimum wagesa) & & & & & 0.10 \\
\hline$\leq 1$ & 20 & 90.0 & 103 & 88.0 & \\
\hline$>1$ & - & - & 14 & 12.0 & \\
\hline Family income (Minimum wages) & & & & & 0.05 \\
\hline$\leq 2$ & 18 & 90.0 & 92 & 82.9 & \\
\hline$>2$ & - & - & 19 & 17.1 & \\
\hline
\end{tabular}

a Minimum wage at the time of the research: $\mathrm{R} \$ 724.00$. 
Table 3

Analysis of unfavorable outcomes in parturients with VDRL reagent test admitted to public maternities according to prenatal care aspects.Fortaleza, Ceará, 2014.

\begin{tabular}{|c|c|c|c|c|c|}
\hline \multirow{3}{*}{ Variables } & \multicolumn{4}{|c|}{ Unfavorable outcomes } & \multirow{3}{*}{$\boldsymbol{P}$} \\
\hline & \multicolumn{2}{|c|}{ Yes } & \multicolumn{2}{|c|}{ No } & \\
\hline & $\mathrm{n}$ & $\%$ & $\mathrm{n}$ & $\%$ & \\
\hline Received prenatal care & & & & & 0.35 \\
\hline Yes & 19 & 95.0 & 115 & 98.3 & \\
\hline No & 01 & 5.0 & 02 & 1.7 & \\
\hline Initiated prenatal care (in weeks) & & & & & 0.10 \\
\hline$\leq 13$ & 04 & 26.7 & 54 & 49.1 & \\
\hline$>13$ & 11 & 73.3 & 56 & 50.9 & \\
\hline Number of prenatal care consultations & & & & & 0.03 \\
\hline$<6$ & 13 & 68.4 & 49 & 42.6 & \\
\hline$\geq 6$ & 06 & 31.6 & 66 & 57.4 & \\
\hline Was tested for VDRL during prenatal care & & & & & 0.69 \\
\hline Yes & 17 & 89.5 & 106 & 92.2 & \\
\hline No & 02 & 10.5 & 09 & 7.8 & \\
\hline 1st VDRL titration $(n=84)$ & & & & & 0.55 \\
\hline$\leq 1: 8$ & 09 & 69.2 & 51 & 60.7 & \\
\hline$>1: 8$ & 04 & 30.8 & 33 & 39.3 & \\
\hline Was tested for the 1 st VDRL in the 1 st trimester & & & & & 0.81 \\
\hline Yes & 07 & 46.7 & 47 & 50.0 & \\
\hline No & 08 & 53.3 & 47 & 50.0 & \\
\hline Was tested for the 2nd VDRL $(n=123)$ & & & & & 0.03 \\
\hline Yes & 04 & 23.5 & 55 & 51.9 & \\
\hline No & 13 & 76.5 & 51 & 48.1 & \\
\hline Was treated adequately & & & & & 0.37 \\
\hline Yes & 05 & 25.0 & 41 & 35.0 & \\
\hline No & 15 & 75.0 & 76 & 65.0 & \\
\hline VDRL titration at the Maternity & & & & & 0.05 \\
\hline$\leq 1: 8$ & 12 & 60.0 & 93 & 79.5 & \\
\hline$>1: 8$ & 08 & 40.0 & 24 & 20.5 & \\
\hline
\end{tabular}

$\mathrm{PN}=$ Prenatal, VRDL= Venereal Disease Research Laboratory. 
Multivariate analysis of the factors associated to the outcome of parturients with VDRL reagent test. Fortaleza, Ceará, 2014.

\begin{tabular}{|c|c|c|c|c|c|c|c|c|}
\hline \multirow{3}{*}{ Variables } & \multirow[b]{3}{*}{$\mathrm{n} / \mathrm{N}$} & \multirow[b]{3}{*}{$\%$} & \multicolumn{6}{|c|}{ Unfavorable outcomes } \\
\hline & & & \multicolumn{3}{|c|}{ Non-adjusted } & \multicolumn{3}{|c|}{ Adjusted } \\
\hline & & & OR & $95 \% \mathrm{Cl}$ & $p$ & OR & $95 \% \mathrm{Cl}$ & $p$ \\
\hline Age (years) & & & & & 0.01 & & & \\
\hline$\leq 29$ & $20 / 20$ & 14.5 & 1 & - & - & - & - & - \\
\hline$>30$ & $91 / 117$ & 77.7 & 0.31 & - & - & - & - & - \\
\hline Number of prenatal consultations & & & & & 0.06 & & & \\
\hline$<6$ & $13 / 20$ & 65.0 & 1 & - & - & - & - & - \\
\hline$\geq 6$ & $50 / 117$ & 42.7 & 0.40 & $(0.12-1.18)$ & - & - & - & - \\
\hline Was tested for the $2^{\text {nd }}$ VDRL test & & & & & 0.05 & 3.54 & $(1.04-15.3)$ & 0.02 \\
\hline Yes & $55 / 117$ & 47.0 & 2.58 & $(0.81-7.75)$ & - & - & - & - \\
\hline No & $04 / 20$ & 20.0 & 1 & - & - & - & - & - \\
\hline $2^{\text {nd }}$ VDRL titration & & & & & 0.05 & 2.15 & $(1.11-11.2)$ & 0.03 \\
\hline$\geq 1: 8$ & $93 / 117$ & 79.4 & 2.58 & $(1.04-15.33)$ & - & - & - & - \\
\hline$<1: 8$ & $12 / 20$ & 60.0 & 1 & - & - & - & - & - \\
\hline
\end{tabular}

$\mathrm{N}=$ total sample size, $\mathrm{n}=$ part of the sample size, $\mathrm{Cl}=$ confidence interval, $\mathrm{OR}=$ Odds Ratio, $\mathrm{VRDL}=$ Venereal Disease Research Laboratory.

with the worst socioeconomic situation. 16,17

Considering these findings, measurements in preventing and controlling this infection in the young population have become critical, since it is very likely that infected women will get pregnant again 18 and, consequently, the birth of children with CS will continue to occur, with possible unfavorable outcomes.

The multivariate analysis may show that the chance of an unfavorable outcome was three times higher in children whose mothers did not undergo the second VDRL test and two times higher in those whose VDRL titration at the maternity was greater than 1:8. These aspects are directly related to the quality of the prenatal care, a situation that already has been so frequently debated in CS studies.

In Brazil, the findings in a hospital-based study found some negative outcomes (fetal or neonatal death, low birth weight, prematurity birth, or neonatal ICU admission) in $33.9 \%$ of the newborns diagnosed with CS, and almost all the women had received prenatal care. 7 These findings reinforce the importance of investing to improve the quality in the healthcare, a situation corroborated by a study carried out in China,which demonstrated that adequate prenatal interventions can greatly contribute in avoiding complications caused by syphilis. 19

In this study, a considerable proportion of women received prenatal care and $94.9 \%$ had three or more consultations. It is noteworthy that the healthcare services have the rapid test (RT) for syphilis available, and this test should be performed on the first and third trimester of the pregnancy. ${ }^{2}$ The RT can provide access to the diagnosis as early as possible, allowing appropriate treatment to be implemented, even if the pregnant woman has had only three prenatal consultations. It is worth noting that the Ministry of Health ( $\mathrm{MH})$ recommends six or more prenatal consultations. 10

Newman et al. 14 , carried out a study in different continents and also found that a large number of women with syphilis who had received prenatal care, the pregnancy resulted in some unfavorable outcome. In these authors' study included women with active syphilis. This occurrence reinforces the findings of this present study which found the odds ratio presenting an unfavorable outcome twice as high in women whose VDRL titration was greater than $1: 8$, which may represent active syphilis. It is important to emphasize the trimester of initiating the prenatal care, since, although it does not show any statistical significance, it was found that the highest proportion of unfavorable outcomes occurred in women who had a late initiation.

The prevalence of the odds ratio for pregnant women with syphilis presents an unfavorable outcome that was three times higher in women who 
did not undergo the second VDRL test, showing the missed opportunities of diagnosing and treating syphilis during the gestational period, a situation verified in another study. ${ }^{20}$ In Brazil, the Ministry of Health, in the attempt to minimize the missed opportunities for testing and treating, recommends that all pregnant women should be tested for syphilis in the first and third trimester of pregnancy and at the time of childbirth, ${ }^{10}$ with the use of RT.

In this study, it was possible to verify that the unfavorable outcomes in parturients with syphilis occurred in women who did not undergo the second VDRL test and whose test titration was greater than 1:8 when performed at the maternity. These data show the importance of ensuring early access to prenatal care and the qualification of this assistance, guaranteeing the testing and treatment for the pregnant women with syphilis, aiming to prevent possible unfavorable outcomes.

Finally, it is worth mentioning that in the bivariate analysis, being a young adult and having a low family income showed a statistically significant association for women with syphilis in having an unfavorable outcome during pregnancy ( $p=0.01$ and $p=0.05$ respectively), reinforcing the importance of these variables as possible predictors of severe circumstances for the baby, a situation also found in all the regions in Brazil7 and in the United States. ${ }^{3}$

Young individuals are more likely to have STIs 21 and, in relation to syphilis, being at the most recent stage of infection, having the existing possibility of transmission. ${ }^{12}$ Age and family income are associated to the minimum access of complementary exams during prenatal care, greatly impairing the quality of this assistance. 22

Therefore, it is necessary to give special attention to young and low income individuals through actions in promoting health and preventing STIs, as well as providing syphilis test and treatment to those who are infected. The epidemic control in this population could effectively contribute in preventing new cases of the infection and its complications.

This study was limited in assessing the outcomes of CS, not addressing associated issues such as treatment and the morbidity of newborns, those who were born of mothers with VDRL reagent. Thus, the important role of the maternity units in preventing late CS sequelae has not been explored.

\section{Authors' contributions}

Araújo MAL and Bertoncini PMRP - designed, produced and reviewed the final version of the article. Andrade RFV and Barros VL - elaborated, critically reviewed the final version of the article. All the authors approved the final version of the manuscript.

\section{References}

1. WHO (World Health Organization). Investment case for eliminating mother-to-child transmission of syphilis. 2012; $1-36$.

2. Brasil. Ministério da Saúde. Secretaria de Vigilância em Saúde. Departamento de Vigilância, Prevenção e Controle das IST, do HIV/Aids e das Hepatites Virais. Protocolo Clínico e Diretrizes Terapêuticas para Atenção Integral às Pessoas com Infecções Sexualmente Transmissíveis. Brasília, DF; 2018.

3. Su JR, Brooks LC, Davis DW, Torrone EA, Weinstock HS, Kamb ML. Congenital syphilis: Trends in mortality and morbidity in the United States, 1999 through 2013. Am J Obstet Gynecol. 2016; 214 (3): 381.e1-381.e9

4. Brasil. Ministério da Saúde. Secretaria de Vigilância em Saúde. Boletim Epidemiológico da Sífilis. Brasília, DF; 2017.

5. WHO (World Health Organization). Global guidence on criteria and processes for validation: elimination of motherto-child transmission (EMTCT) of HIV and syphilis. Geneva; 2014

6. Nonato SM, Melo APS, Guimarães MDC. Syphilis in pregnancy and factors associated with congenital syphilis in
Belo Horizonte-MG, Brazil, 2010-2013. Epidemiol Serv Saúde. 2015; 24: (4): 681-94.

7. Domingues RMSM, Leal M do C. Incidência de sífilis congênita e fatores associados à transmissão vertical da sífilis: dados do estudo Nascer no Brasil. Cad Saúde Pública. 2016; 32 (6): e00082415.

8. Lafetá KRG, Júnior HM, Silveira MF, Paranaíba LMR. Maternal and congenital syphilis, underreported and difficult to control. Rev Bras Epidemiol. 2016; 19 (1): 63-74.

9. Reis GJ, Barcellos C, Pedroso MM, Xavier DR. Diferenciais intraurbanos da sífilis congênita: análise preditiva por bairros do Município do Rio de Janeiro, Brasil. Cad Saúde Pública. 2018; 34 (9): e00105517.

10. Brasil. Ministério da Saúde. Secretaria de Atenção à Saúde. Departamento de Atenção Básica. Atenção ao pré-natal de baixo risco. Brasília, DF; 2012. 318 p.: il. - (Série A. Normas e Manuais Técnicos) (Cadernos de Atenção Básica, $\mathrm{n}^{\mathrm{o}} 32$ ).

11. Brasil. Ministério da Saúde. Secretaria de Atenção à Saúde $\mathrm{D}$ de APE. Gestação de Alto Risco: manual técnico. 5th ed. Brasília, DF; 2012. 302 p. 
12. Brasil. Ministério da Saúde. Secretaria de Vigilância em Saúde. Departamento de Vigilância, Prevenção e controle das Infecções Sexualmente Transmissíveis, do HIV/Aids e das Hepatites Virais. Protocolo Clínico e Diretrizes Terapêuticas para Prevenção da Transmissão Vertical do HIV, Sífilies e Hepatites Virais. Brasília, DF; 2018

13. Dou L, Wang X, Wang F, Wang Q, Qiao Y, Su M, Jin X, Qiu J, Song L, Wang A. Epidemic Profile of Maternal Syphilis in China in 2013. Biomed Res Int. 2016; 2016: 1-9.

14. Newman L, Kamb M, Hawkes S, Gomez G, Say L, Seuc A, Broutet N. Global Estimates of Syphilis in Pregnancy and Associated Adverse Outcomes: Analysis of Multinational Antenatal Surveillance Data. PLoS Med. 2013; 10 (2) e1001396.

15. Magalhães DMS, Kawaguchi IAL, Dias A, Calderon IMP. Sífilis materna e congênita: ainda um desafio. Cad Saúde Pública. 2013; 29 (6): 1109-20

16. Nunes BP, Thumé E, Tomasi E, Duro SMS, Facchini LA. Desigualdades socioeconômicas no acesso e qualidade da atenção nos serviços de saúde. Rev Saúde Pública. 2014; 48 (6): 968-76.

17. Guibu IA, Moraes JC, Guerra AA, Costa EA, Acurcio FA, KS, Karnikowski MGO, Soeiro OM, Leite SN, Álvares J. Características principais dos usuários dos serviços de atenção primária à saúde no Brasil. Rev Saúde Pública. 2017; 51 (Supl. 2): 1-13.
18. Manabe YC, Namale G, Nalintya E, Sempa J, Ratanshi RP, Pakker N, Katabira E. Integration of antenatal syphilis screening in an urban HIV clinic : a feasibility study. BMC Infectious Diseases. 2015; 15 (15): 1-6.

19. Hong FC, Yang YZ, Liu XL, Feng TJ, Liu JB, Zhang CL, Lan LN, Yao MZ, Zhou H. Reduction in mother-to-child transmission of syphilis for 10 years in Shenzhen, China. Sex Transm Dis. 2014; 41 (3): 188-93.

20. Domingues RMSM, Szwarcwald CL, Souza Junior PRB, Leal MC. Prevalência de sífilis na gestação e testagem prénatal: Estudo Nascer no Brasil. Rev Saúde Pública. 2014; 48 (5): 766-74.

21. Araújo MAL, Rocha AFB, Cavalcante EGF, Moura HJ, Galvão MTG, Lopes ACMU. Doenças sexualmente transmissíveis atendidas em unidade primária de saúde no Nordeste do Brasil. Cad Saúde Colet (Rio J.). 2015; 23 (4): 347-53.

22. Tomasi E, Fernandes PAA, Fischer T, Siqueira FCV, Silveira DS, Thumé E, Duro SMS, Saes MO, Nunes BP, Fassa AG, Facchini LA. Qualidade da atenção pré-natal na rede básica de saúde do Brasil: indicadores e desigualdades sociais. Cad Saúde Pública. 2017; 33 (3): 1-11.

Received on April 08, 2018

Final version presented on March 07, 2019

Approved on April 25, 2019 